\title{
Design, development, and in vitro evaluation of sustained release tablet formulations of olmesartan medoxomil
}

\author{
Abstract \\ Objective: The purpose of present research work is to develop the sustained release \\ formulation for Olmesartan medoxomil using $3^{2}$ factorial design. Olmesartan an \\ Antihypertensive agent, angiotensin-II receptor (type AT1) blocker and BCS class-II \\ agent.
}

Methods: Sustained Release tablets of Olmesartan medoxomil were prepared using different quantities of HPMCK4M and Xanthan Gum in combinations by direct compression technique. The concentration of Polymers, HPMCK4M and Xanthan gum required to achieve the drug release was selected as independent variables, $\mathrm{X}_{1}$ and $\mathrm{X}_{2}$ respectively whereas, time required for $10 \%$ of drug release $\left(\mathrm{t}_{10 \%}\right), 50 \%\left(\mathrm{t}_{50 \%}\right), 75 \%$ $\left(\mathrm{t}_{75 \%}\right)$ and $90 \%\left(\mathrm{t}_{90 \%}\right)$ were selected as dependent variables.

Results: Nine formulations were prepared and are evaluated for various pharmacopoeial tests. The results reveals that all formulations were found to be with in the pharmacopoeial limits and In vitro drug release profiles of all formulations were fitted in to various Kinetic models. The statistical parameters like intercept, slope $\&$ correlation coefficient were calculated. Polynomial equations were developed for dependent variables. Validity of developed polynomial equations were checked by designing 2 check point formulations $\left(\mathrm{C}_{1}, \mathrm{C}_{2}\right)$.

Conclusion: According to SUPAC guidelines formulation $\left(\mathrm{F}_{5}\right)$ containing combination of $15 \%$ HPMCK $4 \mathrm{M}$ and $15 \%$ Xanthan gum, is the most identical formulation (similarity factor $\mathrm{f}_{2}=91.979$, dissimilarity factor $\mathrm{f}_{1}=1.546$ \& No significant difference, $\mathrm{t}=0.0338$ ) to marketed product (BENICAR). Best Formulation $\mathrm{F}_{5}$ follows First order, Higuchi's kinetics, and the mechanism of drug release was found to be Non-Fickian Diffusion Anomalous Transport. $(\mathrm{n}=0.828)$

Keywords: olmesartan medoxomil, $3^{2}$ factorial design, sustained release, hpmck $4 \mathrm{~m}$ , xanthan gum, supac, non-fickian diffusion mechanism, first order kinetics
Volume 2 Issue 3 - 2018

\author{
Raghavendra Kumar Gunda,' Prasada Rao \\ Manchineni, ${ }^{2} \mathrm{D}$ Dhachinamoorthi ${ }^{3}$ \\ 'Department of Pharmaceutics, M.A.M College of Pharmacy, \\ India \\ ${ }^{2}$ Department of Pharmaceutical Analysis, M.A.M College of \\ Pharmacy, India \\ ${ }^{3}$ Department of Pharmaceutics, QIS college of Pharmacy, India
}

Correspondence: Raghavendra Kumar Gunda, Department of Pharmaceutics, M.A.M College of Pharmacy, India, Tel +91-9666705894, Email raghav.gunda@gmail.com

Received: May 25, 2018 | Published: June 22, 2018

\section{Introduction}

Enteral route is the most comfortable, extensively used route of administration for both prompt delivery systems and new drug delivery systems. Tablets are the most famous solid formulations available in the market and are preferred by patients and physicians alike. In case of treatment of chronic disease conditions, conventional release formulations are required to be administered in frequent manner and therefore shows patient non-adherence to prescription. ${ }^{1}$ However, ingestion of majority of drugs shows first pass effect and/or first pass hepatic metabolism presystemic elimination by gastrointestinal degradation as a result of which low systemic bioavailability and shorter duration of action and development of non-active or toxic transformed products. ${ }^{2}$ The objective of a sustained release (SR) dosage form is to maintain $\mathrm{C}_{\mathrm{SS}}$ levels for prolonged period. Systems that are designated as modified release/timed release can also be considered as attempts at achieving prolonged drug delivery. ${ }^{3-6}$ SR formulations offers greater reduction in dosing frequency in comparison with immediate release formulations. ${ }^{7}$ SR formulations afford advantage over prompt release formulations by optimising biopharmaceutical, pharmacokinetic and pharmacodynamic properties of drug. The utilization of macromolecules like polymers in modulating the rate of drug release has turn to an essential tool in the product development of pharmaceutical formulations. Numerous reports over many years reveals that they play key role in the release of drugs from dosage form for various drugs. ${ }^{8}$ Natural polymers preferred primarily because they were economic, high drug holding capacity, high thermal stability, non-carcinogenicity, mucoadhesivity, biodegradable, biocompatible, broad regulatory acceptance and ease of compression. Various gums and mucilages were used for the development of sustained release formulations in such as gums (xanthan, tragacanth, guar), pectin, alginates etc. cellulose derivatives such as HPC, HPMC, CMC, SCMC have been widely used as release retardants in the formulation of prolonged release dosage forms. The future of novel drug delivery systems (SR) is promising in arena like chronopharmacotherapeutic delivery system, mucoadhesive system, chronopharmacokinetic approach, targeted drug delivery approach, particulate system that provide high assurance and adoptability. Sustained release oral formulations by Direct Compression (DC) method was a simple approach due to its rapid production, Easer, No degradative effects occurred during manufacturing, compliance. ${ }^{7}$ The suitability of drug candidates for sustained release system based on biopharmaceutical, pharmacokinetic and pharmacodynamic properties of it. numerous studies have been reported in the literature regarding the utilisation 
of hydrophilic polymers in the formulation of Sustained drug delivery systems for various drugs. ${ }^{8}$ Natural polymers preferred due to their economic, readily available, abitity for chemical modifications, non-carcinogenicity, mucoadhesivity, protein binding and ease of compression. ${ }^{9-10}$ This led to its used as pharmaceutical aid modified drug delivery system. guar gum, tragacanth gum, xanthan gum, pectin, alginates etc were used in the development of SR formulations for last few decades. Semi synthetic polymers such as CMC, SCMC, HPC, HPMC have been extensively employed as polymer in the development sustained release formulations. The future of SR formulations is promising in some area like Chronopharmacotherapeutic delivery system, targeted drug delivery system, that provide high promise and acceptability. Oral SR formulations by Direct Compression technique was a simple approach of manufacturing proved to be rational due to its ease, compliance, faster production, bypass hydrolytic or oxidative reactions occurred during manufacture of dosage forms. ${ }^{11}$

\section{Drug profile and rationality for experimental design}

In the current research work a sustained release formulation of Olmesartan medoxomil has been developed that makes reduced dosing frequency. Olmesartan medoxomil was a angiotensin-II receptor $\left(\mathrm{AT}_{1}\right)$ blocker which results vasoconstrictor and aldosterone-secreting effects of angiotensin-II were blocked. Used in the treatment of mild to moderate Hypertension. It is weakly basic, Lipophilic (BCS-II). the oral bioavailability was founded to be $26 \%$. Thus, there is a need to improve rate of drug release. Hence, the work was performed to design, formulate and evaluate sustained release tablet formulation of Olmesartan medoxomil and had an aim that final best formulation should meet objective of present work. ${ }^{12,13}$ It is an important issue is to design an best formulation with an considerable rate of release in a short moment and minimum heuristics. Response surface morphology (RSM) with polynomial equation based concept has been prominently used. It is used only less significant factors are involved in optimization process. Hence an attempt is made in this study to design SR tablet formulations of Olmesartan medoxomil using HPMCK4M and Xanthan gum by using $3^{2}$ Factorial design techniques. The significant variables (Independent variables) such as quantity of HPMCK4M and Xanthan gum and dependent variables, i.e. $\mathrm{t}_{10 \%}, \mathrm{t}_{50 \%}, \mathrm{t}_{75 \%}, \mathrm{t}_{90 \%}$, (Time taken for dissolution $10 \%, 50 \%, 75 \%, 90 \%$ of drug respectively). ${ }^{14,15}$

\section{Materials and methods}

Materials used in research work were procured from the various sources. Olmesartan medoxomil was a gift sample from Aurobindo pharma Ltd, Hyderabad, India. HPMCK4M, Xanthan gum, MCC and Lactose were procured from Loba Chemie Pvt.Ltd, Mumbai. Other excipients such as magnesium stearate, Talc were procured from S.D. Fine Chem. Ltd., Mumbai.

\section{Design, development of olmesartan medoxomil sustained release formulations}

A3 level, 2 factor experimentation design ( $3^{2}$ factorial design) describe the proportion in which the independent variables quantities of HPMCK4M and Xanthan gum were used in research work The time required for $10 \%\left(\mathrm{t}_{10 \%}\right), 50 \%\left(\mathrm{t}_{50 \%}\right), 75 \%\left(\mathrm{t}_{75 \%}\right)$ and $90 \%\left(\mathrm{t}_{90 \%}\right)$ drug release were opted as dependent variables. Significance terms were chosen at $95 \%$ confidence interval $(\mathrm{p}<0.05)$ for Final Equations. Polynomial equations were developed for $\mathrm{t}_{10 \%}, \mathrm{t}_{50 \%}, \mathrm{t}_{75 \%}, \mathrm{t}_{90 \%}$, according to the Linear step-wise backward Regression Analysis Technique. The 3 levels of factor $\mathrm{X}_{1}(\mathrm{HPMCK} 4 \mathrm{M})$ at $10 \%, 15 \%, 20 \%$ concentrations.
3 levels of factor $\mathrm{X}_{2}$ (Xanthan gum) at 10\%, 15\%,20\% concentrations (\% with respect to average weight tablet). Totally 9 formulations were designed and prepared using trail run combinations of the two factors i.e $\mathrm{X}_{1}, \mathrm{X}_{2}$ as per experimental design and evaluated to find out the significance of combined effects of $\mathrm{X}_{1}, \mathrm{X}_{2}$ to select the best combination and to optimise.

\section{Manufacture of olmesartan medoxomil sustained release tablet formulations}

Olmesartan medoxomil SR Tablets were prepared by Direct Compression method. Composition of each Tablet was shown in Table 2. All ingredients required for formulation were collected and weighed accurately and passed through sieve no 40 . They were mixed uniformly in a poly bag or triturate for 10-15minutes. magnesium stearate was added to the powder blend and then again mix for 4-5min, Blend was subjected to compression by using 8 station rotary tablet compressor ( Minipress, RIMEK), Ahmedabad) using 8mm circular punches and same hardness used for required number of tablets. Compressed tablets were evaluated as per official standards and unofficial tests. Tablets were packaged in air tight, light resistance and moisture proof containers.

\section{Experimental design}

Experimental design used in experimentation for the optimization of release retardants concentration such as, quantity of HPMCK 4M was labelled as $\mathrm{X}_{1}$ and quantity of Xanthan gum was labelled as $\mathrm{X}_{2}$. Formulation design was summarized in Table 1. 3levels for the quantity of HPMCK $4 \mathrm{M}$ were selected and coded as $-1=10 \%, 0=15 \%$, $+1=20 \%$. Three levels for the quantity of Xanthan gum were selected and coded as $-1=10 \%, 0=15 \%,+1=20 \%$. Formulae for all the factorial batches were given in Table 2 .

Table I Experimental design layout

\begin{tabular}{lll}
\hline Formulation code & $\mathbf{X}_{1}$ & $\mathbf{X}_{2}$ \\
\hline $\mathrm{F}_{1}$ & 1 & 1 \\
$\mathrm{~F}_{2}$ & 1 & 0 \\
$\mathrm{~F}_{3}$ & 1 & -1 \\
$\mathrm{~F}_{4}$ & 0 & 1 \\
$\mathrm{~F}_{5}$ & 0 & 0 \\
$\mathrm{~F}_{6}$ & 0 & -1 \\
$\mathrm{~F}_{7}$ & -1 & 1 \\
$\mathrm{~F}_{8}$ & -1 & 0 \\
$\mathrm{~F}_{9}$ & -1 & -1 \\
$\mathrm{C}_{1}$ & -0.5 & -0.5 \\
$\mathrm{C}_{2}$ & +0.5 & +0.5 \\
\hline
\end{tabular}

\section{Evaluation of olmesartan medoxomil sr tablet} formulations

Hardness: This was performed by using Monsanto Hardness Tester. The force at which diametric breakage of tablet was occurred noted as hardness. A hardness of about $2-4 \mathrm{~kg} / \mathrm{cm}^{2}$ is preferred for mechanical stability.

Friability: The test was carried out with the help of Roche friabilator. 
A sample of 20 tablets was taken. Their initial weight was noted. These are dedusted in a drum at a rate of $25 \mathrm{rpm}$ for 4 minutes and weighed again. Percentage friability was determined from the loss in weight as given in equation as below. The weight loss should not be $>1 \%$.

Friability $(\%)=[($ Initial weight - Final weight $) /($ Initial weight $)]$ $\mathrm{x} 100$

Content uniformity: A sample of 20 tablets was chosen randomly \& the $\%$ drug content was determined, the tablets content should be in the range of $100 \pm 15 \%$ of the labelled amount can be considered as the test was passed.

Assay: A sample of 20 tablets collected and subjected to pulverisation. Powder equivalent to $40 \mathrm{mg}$ was dissolved in $1 \mathrm{dL}$ of phosphate buffer $\mathrm{pH}$ 6.8, subjected to agitation to get more solubilisation. The solution was filtered through a $0.45 \mu$ membrane filter, diluted suitably and the absorbance of final solution was measured by using UV-Visible Spectrophotometer at $257 \mathrm{~nm}$ by employing phosphate buffer $\mathrm{pH} 6.8$ as blank.

Thickness: This test was performed by using vernier calipers by placing the tablet between two arms of the vernier calipers. Final result was recorded

\section{In-vitro drug release study}

The In vitro drug release study was performed by using USP XXIII type-II dissolution test apparatus (Paddle type) using $900 \mathrm{ml}$ of $0.1 \mathrm{~N}$ $\mathrm{HCl}$ as dissolution medium for initial 2 hours followed by phosphate buffer $\mathrm{pH} 6.8$ at $50 \mathrm{rpm}$ and temperature $37 \pm 0.5^{\circ} \mathrm{C}$ as standard set of conditions specified by monograph for SR Formulations. At predetermined time intervals, $5 \mathrm{ml}$ of the samples were withdrawn by means of a syringe fitted with a pre-filter, the volume withdrawn at each interval was replaced with same quantity of fresh dissolution medium. The resultant samples were analyzed for the absorbance at $257 \mathrm{~nm}$ using UV Visible spectrophotometer after appropriate dilutions. The determinations were performed in triplicate $(n=3)$.

\section{Kinetic modeling of drug release}

The dissolution profile of formulations was fitted in to zero-order, first-order, Higuchi and Korsmeyer-peppas models to know the pattern, order of drug release and mechanism. ${ }^{8,16,17}$

Table 2 Formulae for the preparation of olmesartan medoxomil sustained release tablets

\begin{tabular}{|c|c|c|c|c|c|c|c|c|c|}
\hline \multirow{2}{*}{ Name of Ingredients } & \multicolumn{9}{|c|}{ Quantity of ingredients per each tablet (mg) } \\
\hline & $\mathbf{F}_{1}$ & $\mathbf{F}_{2}$ & $\mathbf{F}_{3}$ & $\mathbf{F}_{4}$ & $\mathbf{F}_{5}$ & $\mathbf{F}_{6}$ & $\mathbf{F}_{7}$ & $\mathbf{F}_{8}$ & $\mathbf{F}_{9}$ \\
\hline Olmesartan medoxomil & 40 & 40 & 40 & 40 & 40 & 40 & 40 & 40 & 40 \\
\hline Mannitol & 85 & 97.5 & 110 & 97.5 & 110 & 122.5 & 110 & 122.5 & 135 \\
\hline $\begin{array}{l}\text { Microcrystalline Cellulose } \\
\mathrm{pH}-103\end{array}$ & 20 & 20 & 20 & 20 & 20 & 20 & 20 & 20 & 20 \\
\hline HPMCK4M & 50 & 50 & 50 & 37.5 & 37.5 & 37.5 & 25 & 25 & 25 \\
\hline Xanthan gum & 50 & 37.5 & 25 & 50 & 37.5 & 25 & 50 & 37.5 & 25 \\
\hline Magnesium Stearate & 3 & 3 & 3 & 3 & 3 & 3 & 3 & 3 & 3 \\
\hline Talc & 2 & 2 & 2 & 2 & 2 & 2 & 2 & 2 & 2 \\
\hline Total Weight & 250 & 250 & 250 & 250 & 250 & 250 & 250 & 250 & 250 \\
\hline
\end{tabular}

\section{Results and discussion}

Sustained release formulations of Olmesartan medoxomil were prepared and optimized by $3^{2}$ factorial design in order to screen the best combination of different drug release rate modifiers, HPMCK4M, Xanthan gum and also to achieve objective of present research work. The 2 factorial variables utilized in the development of formulations are, quantities of HPMCK4M \& Xanthan gum were opted as independent variables $\left(\mathrm{X}_{1}, \mathrm{X}_{2}\right)$, and In vitro dissolution characteristics such as $t_{100 \%}, t_{50 \%}, t_{75 \%} \& t_{90 \%}$ considered as dependent variables 9 formulations were designed and formulated utilizing $3^{2}$ factorial design and all the formulations containing $40 \mathrm{mg}$ of Olmesartan medoxomil as dose. All the tablets were subjected to various official tests such as mean hardness, friability, drug content, mean thickness and results are summarised in Table 3 . The hardness of tablets was found to be $5.127 \pm 0.409-6.068 \pm 0.413 \mathrm{Kg} / \mathrm{cm}^{2}$. \%Weight loss in for formulations less than $0.44 \%$. Drug content factorial formulations was found to be within acceptable range only. In vitro drug release studies were done for factorial batches using $0.1 \mathrm{~N} \mathrm{HCl}$ for initial 2hours followed by phosphate buffer $\mathrm{pH} 6.8$ as a dissolution media at $50 \mathrm{rpm}$ and $37 \pm 0.5^{\circ} \mathrm{C}$. The In vitro dissolution profiles of tablets were shown in Figure 1-4 (Kinetic Plots) and the Statistical values for kinetic models were tabulated in Table 4. \%Cumulative Drug release for trial batches $\mathrm{F}_{1}-\mathrm{F}_{9}$ at $12 \mathrm{Hr}$ were found to be $91.172-96.628 \%$. From the result it reveals that the rate of drug release was higher for batches containing Low level of $\mathrm{X}_{1}$ compared with others, due to High quantity of polymer results drug may have entrapped within a polymer matrix causing a decrease in release rate. Therefore, predicted release of drug can be resulted by manipulating the quantities of $X_{1}, X_{2}$. Formulation $\mathrm{F}_{5}$ containing $37.5 \mathrm{mg}$ of HPMCK4M, 37.5mg of Xanthan gum exhibited promising kinetic values $\left(\mathrm{t}_{10 \%=} 0.338 \mathrm{~h}, \mathrm{t}_{50 \%=} 2.234 \mathrm{~h}\right.$, $\mathrm{t}_{75 \%=} 4.467 \mathrm{~h}, \mathrm{t}_{90 \%=} 7.420 \mathrm{~h}$ ). The variation in initial rapid release of drug is due to difference in the viscosity of the polymeric mixtures. As we know that viscosity of polymer is inversely proportional to the rate of drug release, variation in the viscosity is due the formation of thicker gel layer in formulation. ${ }^{18}$ The In vitro drug release profile of Olmesartan medoxomil SR tablet formulations was subjected to goodness of fit test by linear backward step-wise regression analysis according to kinetic / mathematical models to know the drug release mechanism. Kinetic plots shown in Figure 1-4. It was known that from the above results dissolution profile of most of batches follows First 
order kinetics with co-efficient of determination $\left(\mathrm{R}^{2}\right)$ values above 0.972 (0.972-0.979). The values of $r$ of factorial batches for Higuchi's kinetics was found to be $0.953-0.964$, which confers that the data fitted well to Higuchi's square root of time equation confirming the release followed diffusion mechanism. Kinetic data also treated for Peppas equation, the slope (n) values $0.626-0.887$ that proves Non-
Fickian diffusion mechanism (anomalous drug transport). Polynomial equations were derived for dependent variables by backward stepwise linear regression analysis with the help of PCP Disso software and kinetic plots were constructed by using SIGMAPLOT V13 software. The Kinetic parameters for factorial formulations $F_{1}$ to $F_{9}$ were shown in Table 5 .

Table 3 Post-compression parameters

\begin{tabular}{lllllll}
\hline S. No & Formulation Code & Hardness $\left(\mathbf{k g} / \mathbf{c m}^{2}\right)$ & $\begin{array}{l}\text { Thickness } \\
(\mathbf{m m})\end{array}$ & Friability $(\%)$ & \%Weight variation & Drug content $(\%)$ \\
\hline $\mathrm{I}$ & $\mathrm{F}_{1}$ & $5.252 \pm 0.43$ & $3.98 \pm 0.123$ & $0.259 \pm 0.07$ & $249.42 \pm 0.139$ & $96.84 \pm 1.6$ \\
2 & $\mathrm{~F}_{2}$ & $5.127 \pm 0.4 \mathrm{II}$ & $4.02 \pm 0.13$ & $0.357 \pm 0.03$ & $249.80 \pm 1.35$ & $98.56 \pm 1.5$ \\
3 & $\mathrm{~F}_{3}$ & $5.504 \pm 0.4 \mathrm{II}$ & $4.135 \pm 0.122$ & $0.398 \pm 0.05$ & $251.68 \pm 1.35$ & $100.7 \pm 1.59$ \\
4 & $\mathrm{~F}_{4}$ & $6.07 \pm 0.413$ & $4.22 \pm 0.12$ & $0.439 \pm 0.07$ & $252.38 \pm 1.44$ & $100.24 \pm 1.5$ \\
5 & $\mathrm{~F}_{5}$ & $5.93 \pm 0.395$ & $4.28 \pm 0.125$ & $0.361 \pm 0.024$ & $252.85 \pm 1.4$ & $100.89 \pm 1.4$ \\
6 & $\mathrm{~F}_{6}$ & $5.957 \pm 0.395$ & $4.25 \pm 0.12$ & $0.443 \pm 0.05$ & $253.8 \pm 1.4$ & $102.18 \pm 1.51$ \\
7 & $\mathrm{~F}_{7}$ & $6.066 \pm 0.4 \mathrm{I}$ & $4.22 \pm 0.064$ & $0.439 \pm 0.04$ & $252.38 \pm 1.44$ & $100.24 \pm 1.45$ \\
8 & $\mathrm{~F}_{8}$ & $5.95 \pm 0.39$ & $4.28 \pm 0.12$ & $0.361 \pm 0.01$ & $252.85 \pm 1.4$ & $100.89 \pm 1.35$ \\
9 & $F_{9}$ & $5.955 \pm 0.395$ & $4.25 \pm 0.115$ & $0.443 \pm 0.02$ & $253.80 \pm 1.45$ & $102.18 \pm 1.44$ \\
\hline
\end{tabular}

Table 4 Statistical parameters

\begin{tabular}{|c|c|c|c|c|c|c|c|c|c|c|c|c|c|}
\hline \multirow[t]{2}{*}{ S. No } & \multirow[t]{2}{*}{$\begin{array}{l}\text { Formulation } \\
\text { code }\end{array}$} & \multicolumn{2}{|c|}{ Zero order } & \multicolumn{2}{|c|}{ First order } & \multicolumn{2}{|r|}{ Higuchi } & \multicolumn{4}{|c|}{ Korsmeyer-peppas } & \multirow[b]{2}{*}{$b$} & \multirow[b]{2}{*}{$r$} \\
\hline & & $\mathrm{a}$ & $\mathrm{b}$ & $r$ & a & $\mathrm{b}$ & $r$ & $\mathrm{a}$ & $\mathrm{b}$ & $r$ & $\mathrm{a}$ & & \\
\hline I & $\mathrm{F}_{1}$ & 1.917 & 9.257 & 0.98 & 2.116 & 0.1 & 0.979 & 23.907 & 33.888 & 0.957 & 0.626 & 1.392 & 0.992 \\
\hline 2 & $\mathrm{~F}_{2}$ & 0.544 & 9.397 & 0.978 & 2.13 & 0.112 & 0.978 & $23.4 I 4$ & 34.76 & 0.963 & 0.678 & 1.36 & 0.989 \\
\hline 3 & $\mathrm{~F}_{3}$ & 0.412 & 9.366 & 0.978 & 2.131 & 0.114 & 0.978 & 2.507 & 34.708 & 0.964 & 0.808 & 1.206 & 0.992 \\
\hline 4 & $\mathrm{~F}_{4}$ & 0.437 & 9.587 & 0.972 & 2.133 & 0.118 & 0.976 & 23.771 & 35.465 & 0.956 & 0.777 & 1.241 & 0.99 \\
\hline 5 & $\mathrm{~F}_{5}$ & 0.833 & 9.748 & 0.971 & 2.16 & 0.135 & 0.975 & 23.292 & 36.259 & 0.96 & 0.828 & 1.206 & 0.989 \\
\hline 6 & $\mathrm{~F}_{6}$ & 0.993 & 9.74 & 0.97 & 2.157 & 0.135 & 0.973 & 23.154 & 36.252 & 0.96 & 0.842 & I. 188 & 0.989 \\
\hline 7 & $\mathrm{~F}_{7}$ & 0.228 & 9.753 & 0.965 & 2.137 & 0.127 & 0.972 & 23.726 & 36.188 & 0.953 & 0.828 & 1.195 & 0.988 \\
\hline 8 & $F_{8}$ & 1.498 & 9.913 & 0.965 & 2.168 & 0.147 & 0.973 & 23.248 & 36.982 & 0.957 & 0.873 & 1.165 & 0.988 \\
\hline 9 & $\mathrm{~F}_{9}$ & 1.658 & 9.906 & 0.964 & 2.165 & 0.146 & 0.973 & 23.11 & 36.975 & 0.957 & 0.887 & I.I 148 & 0.987 \\
\hline
\end{tabular}

$\mathrm{FI}$ to $\mathrm{F} 9$ are factorial formulations, r-correlation coefficient, a-Intercept, b-Slope

Table 5 Dissolution parameters of olmesartan medoxomil sr tablets

\begin{tabular}{llllll}
\hline \multirow{2}{*}{ S.No } & Formulation code & \multicolumn{3}{l}{ Kinetic parameters } \\
\cline { 3 - 6 } & & T50\% (Hrs) & T10\% (Hrs) & T90\% (Hrs) & T75\% (Hrs) \\
\hline $\mathrm{I}$ & $\mathrm{F}_{1}$ & 3.006 & 0.457 & 9.994 & 6.017 \\
2 & $\mathrm{~F}_{2}$ & 2.698 & 0.41 & 8.961 & 5.397 \\
3 & $\mathrm{~F}_{3}$ & 2.632 & 0.4 & 8.75 & 5.264 \\
4 & $\mathrm{~F}_{4}$ & 2.554 & 0.388 & 8.475 & 5.105 \\
5 & $\mathrm{~F}_{5}$ & 2.235 & 0.338 & 7.421 & 4.464 \\
6 & $\mathrm{~F}_{6}$ & 2.235 & 0.34 & 7.425 & 4.475 \\
7 & $\mathrm{~F}_{7}$ & 2.376 & 0.361 & 7.894 & 4.751 \\
8 & $\mathrm{~F}_{8}$ & 2.052 & 0.312 & 6.819 & 4.104 \\
9 & $\mathrm{~F}_{9}$ & 2.057 & 0.313 & 6.83 & 4.115 \\
\hline
\end{tabular}




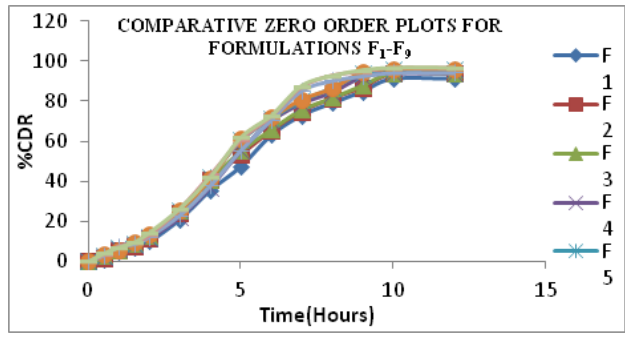

Figure I Comparative zero order plots for FI-F9

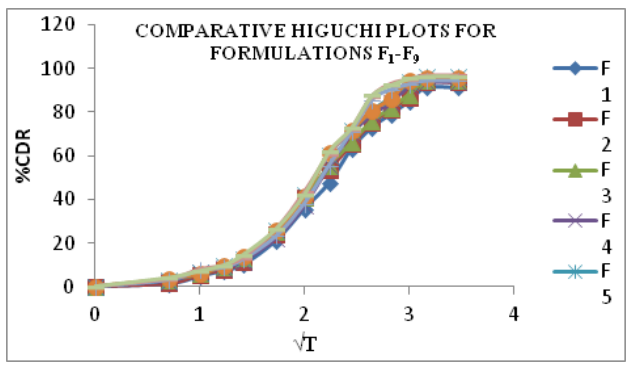

Figure 3 Comparative higuchi plots for FI-F9.

Polynomial equation for $3^{2}$ full factorial designs is given in Equation

$$
\mathrm{Y}=\mathrm{b}_{0}+\mathrm{b}_{1} \mathrm{X}_{1}+\mathrm{b}_{2} \mathrm{X}_{2}+\mathrm{b}_{12} \mathrm{X}_{1} \mathrm{X}_{2}+\mathrm{b}_{11} \mathrm{X}_{1}^{2}+\mathrm{b}_{22} \mathrm{X}_{2}^{2} \cdots
$$

Where, $\mathrm{Y}$ is dependent variable, $\mathrm{b}_{0}$ arithmetic mean response of nine batches, and $b_{1}$ estimated co-efficient for factor $X_{1}$. The main effects $\left(X_{1}\right.$ and $\left.X_{2}\right)$ represent the average result of changing one factor at a time from its low to high value. The interaction term $\left(\mathrm{X}_{1} \mathrm{X}_{2}\right)$ shows how the response changes when two factors are simultaneously changed. The polynomial terms $\left(\mathrm{X}_{1}^{2}\right.$ and $\left.\mathrm{X}_{2}^{2}\right)$ are included to investigate nonlinearity. Validity of derived equations was verified by preparing Two Check point Formulations of Intermediate concentration $\left(\mathrm{C}_{1}, \mathrm{C}_{2}\right)$.

The equations for $t_{10 \%}, t_{50 \%}, t_{75 \%}$ and $t_{90 \%}$ developed as follows,

$\mathrm{Y}_{1}=0.369+0.047 \mathrm{X}_{1}+0.0257 \mathrm{X}_{2}+0.002 \mathrm{X}_{1} \mathrm{X}_{2}+0.0197 \mathrm{X}_{1}^{2}+0.023 \mathrm{X}_{2}^{2}$ (for $\mathrm{t}_{10 \%}$ )

$$
\mathrm{Y}_{2}=2.427+0.309 \mathrm{X}_{1}+0.169 \mathrm{X}_{2}+0.013 \mathrm{X}_{1} \mathrm{X}_{2}+0.131 \mathrm{X}_{1}^{2}+0.149 \mathrm{X}_{2}^{2}
$$
(for $\mathrm{t}_{50 \%}$ )

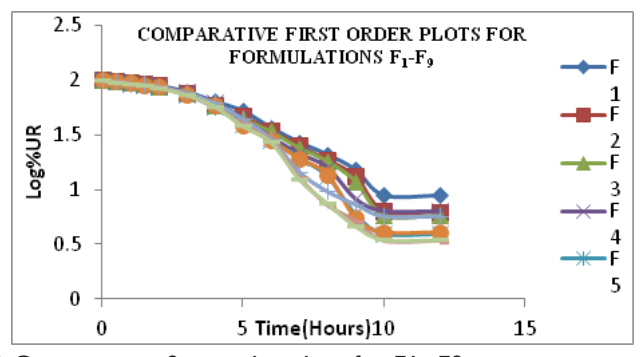

Figure 2 Comparative first order plots for FI-F9

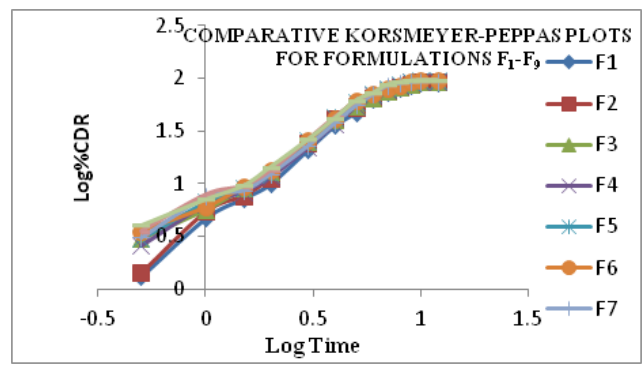

Figure 4 Comparative korsmeyer-peppas plots for FI-F9.

$$
\begin{aligned}
& \mathrm{Y}_{3}=4.853+0.618 \mathrm{X}_{1}+0.337 \mathrm{X}_{2}+0.027 \mathrm{X}_{1} \mathrm{X}_{2}+0.261 \mathrm{X}_{1}{ }^{2}-0.298 \mathrm{X}_{2}^{2} \\
& \mathrm{Y}_{4}=8.064+1.027 \mathrm{X}_{1}+0.560 \mathrm{X}_{2}+0.045 \mathrm{X}_{1} \mathrm{X}_{2}+0.434 \mathrm{X}_{1}^{2}+0.495 \mathrm{X}_{2}^{2}
\end{aligned}
$$

The $+^{\text {ve }}$ sign for co-efficient of $\mathrm{X}_{1}$ in $\mathrm{Y}_{1} \mathrm{Y}_{2} \mathrm{Y}_{3}$ and $\mathrm{Y}_{4}$ equations indicates that, quantity of $\mathrm{X}_{1}$ is directly proportional to $\mathrm{Y}$ values. Alternatively the data indicate that both $\mathrm{X}_{1}, \mathrm{X}_{2}$ influences the dependent variables. From the results it can be concluded that, and increase in the amount of the polymer leads to decrease in release rate of the drug and drug release pattern may be changed by appropriate selection of the $X_{1}$ and $X_{2}$ levels. The Dissolution parameters for predicted from the polynomial equations derived and those actual observed from experimental results are summarised in Table 6. The closeness of Predicted and Observed values for dependent variables

\begin{tabular}{|c|c|c|c|c|c|c|c|c|}
\hline \multirow{2}{*}{ Formulation code } & \multicolumn{4}{|c|}{ Predicted value } & \multicolumn{4}{|c|}{ Actual observed value } \\
\hline & TI0\% (H) & $\mathrm{T} 50 \%(\mathrm{H})$ & $\begin{array}{l}\text { T75\% } \\
\text { (H) }\end{array}$ & T90\% (H) & TI0\% (H) & $\begin{array}{l}\text { T50\% } \\
\text { (H) }\end{array}$ & $\begin{array}{l}\text { T75\% } \\
\text { (H) }\end{array}$ & $\begin{array}{l}\text { T90\% } \\
\text { (H) }\end{array}$ \\
\hline$C_{1}$ & 0.345 & 2.261 & 4.522 & 7.514 & 0.346 & 2.271 & 4.534 & 7.528 \\
\hline $\mathrm{C}_{2}$ & 0.417 & 2.739 & 5.477 & 9.101 & 0.42 & 2.742 & 5.497 & 9.111 \\
\hline
\end{tabular}
shows the validity of derived equations. The final best (Optimised) formulation $\left(\mathrm{F}_{4}\right)$ is compared with marketed product (BENICAR) shows similarity factor $\left(f_{2}\right) 91.979$, difference factor $\left(f_{1}\right) 1.546$ (There is no significant difference in drug release because $t_{\text {cal }}$ is $\left.<0.05\right)$.

Table 6 Dissolution parameters for predicted and observed values for check point formulations

\section{Conclusion}

release was decreases and both of these polymers can be used in

The current research study envisions the utility of polymers such as HPMCK 4M and Xanthan gum in the Formulation design and development of sustained release tablet formulations of Olmesartan medoxomil utilizing the $3^{2}$ factorial design. From the results it reveals that as the quantity of $\mathrm{X}_{1}$ (HPMC) increases the rate of drug combination with the drug which may be more helpful in obtaining the desired rate of drug release for prolonged period of time. The final best formulation followed Higuchi's kinetics while the drug release mechanism was found to be Non-Fickian Diffusion (Anomalous Transport), First order release type. On the basis of post compression 
parameters, the formulation $\mathrm{F}_{5}$ may be used one time administration in the management of hypertension and to reduce the risk of stroke, Herat attack, cardiovascular disease. This may improve the patient compliance by reducing the dosing frequency.

\section{Acknowledgements}

The author would like to thank the Management, Principal \& Staff of M.A.M College of Pharmacy, Kesanupalli (v) Narasaraopet, Guntur (D.t), A.P., India for providing support for successful completion of research work.

\section{Conflict of inertest}

Author declares that there is no conflict of interest

\section{References}

1. Swati J, Neelesh Kumar M, Akhlesh K, et al. Development and evaluation of sustained release matrix tablet of lamivudine. International Journal of Pharmaceutical Sciences and Research. 2011;2(1):454-461.

2. Ruben Singh. Design, Formulation and in Vitro Evaluation of Lamivudine Hcl Sustained Release Tablets. International Journal of Research in Pharmaceutical and Nano Sciences. 2014;3(2):113-121.

3. Raghavendra K, Suresh Kumar JN, Ajay Babu, et al. Formulation Development and Evaluation of Lamotrigine Sustained Release Tablets Using $3^{2}$ Factorial Design. International Journal of Pharmaceutical Sciences and Research. 2015;8(4):713-724.

4. Bankar GS, Rhodes CT. Eds. Modern Pharmaceutics. 3rd ed. Marcel Dekker, Inc. New York. 1996;59(6):668-669.

5. Lachmann L, Lieberman HA, Kanig JL. The Theory \& Practice of Industrial Pharmacy. India: Bombay; 1991. p. 1-430.

6. Raghavendra K, Suresh Kumar JN. Formulation Development and Evaluation of Zidovudine Sustained Release Tablets Using $3^{2}$ Factoria Design. Der Pharmacia Sinica. 2015;6(6):59-67.

7. Suresh Kumar JN, Satyaprasad B, Chandan K, et al. Formulation Development and Evaluation of Metoprolol Succinate Sustained Release Tablets Using $3^{2}$ Factorial Design. Der Pharmacia Lettre.
2015;7(7):148-157.

8. Raghavendra K. Formulation Development and Evaluation of Rosiglitazone Maleate Sustained Release Tablets Using $3^{2}$ Factorial Design. International Journal of Pharm Tech Research. 2015;8(4):713-724.

9. Prakash P, Porwal M, Saxena A. Role of natural polymers in sustained release drug delivery system: application and recent approaches. International Research Journal of Pharmacy. 2011;2(9):6-11.

10. Raghavendra K, Suresh Kumar JN, Chandan K. Design, Formulation and Evaluation of Atenolol Gastro Retentive Floating Tablets. Asian Journal of Pharmaceutics. 2015;9(4):S34-S42.

11. Bankar GS, Rhodes CT. Modern Pharmaceutics. 4th ed. USA: Marcel Dekker, Inc.; 2003. p. 503-505.

12. Kota Ravi Kumar, Gande Suresh. Development and Evaluation of Olmesartan medoxomil Controlled release floating microspheres using natural gums. International Journal of pharmaceutical sciences and Nanotechnology. 2017;10(4):3788-3793.

13. Sruthy PN, Anoop KR. Formulation and Evaluation of Olmesartan medoxomil floating tablets. International Journal of Pharmacy and Pharmaceutical Sciences. 2013;5(3):691-696.

14. Kharia AA, Hiremath SN, Omray K, et al. Design and Optimization of Floating Drug Delivery System of Acyclovir. Indian Journal of Pharmceutical Sciences. 2010;72(5):599-606.

15. Raghavendra K, Suresh Kumar JN, Satyanarayana V, et al. Formulation design, optimization and evaluation of domperidone maleate gastro retentive floating tablets. Der Pharmacia Lettre. 2016;8(4):198-207.

16. Higuchi T. Mechanism of sustained-action medication. Theoretical analysis of rate of release of solid drugs dispersed in solid matrices. Journal of Pharmaceutical Sciences. 1963;51:1145-1149.

17. Peppas NA. Analysis of Fickian and non-Fickian drug release from polymers. Pharmaceutica Acta Helvetiae. 1985;60(4):110-111.

18. Dortunc B, Gunal N. Release of acetazolamide from swellable HPMC matrix tablets. Drug Development and Industrial Pharmacy. 1997;23(12):1245-1249. 